\title{
DAVID FOSTER WALLACE E FRANZ KAFKA EM DIÁLOGO: UMA INTRODUÇÃO
}

\section{DAVID FOSTER WALLACE AND FRANZ KAFKA IN DIALOGUE: AN INTRODUCTION}

\author{
Diego Gomes do Valle*
}

Resumo: O presente artigo busca analisar comparativamente momentos e formas presentes em algumas obras de David Foster Wallace e Franz Kafka, especialmente Graça infinita e A metamorfose. Para esta análise, selecionamos textos críticos de e sobre os autores escolhidos, bem como outras obras que possam dialogar com os temas evocados. Os tópicos escolhidos para a comparação foram a questão do humor, que Wallace analisa em Kafka e que podemos perceber no primeiro. O ensaio de Wallace sobre Kafka, neste sentido, servirá de base para esclarecer a ambos, já que Wallace aponta aquilo que lhe pareceu relevante, a saber: o humor literal de Kafka. Também a questão paterna, bem como os traumas dela derivados, mereceram nossa atenção. Assim, almejamos aproximar os autores de modo a ampliar e aclarar ambos e suas relações com o próprio fazer literário.

Palavras-chave: David Foster Wallace; Graça infinita; Franz Kafka.

AвSTRACT: This article seeks to analyze comparatively moments and forms present in some works of David Foster Wallace and Franz Kafka, especially Infinite Grace and The Metamorphosis. For this analysis, we selected critical texts from and about the authors chosen, as well as other works that can dialogue with the themes evoked. The topics chosen for comparison were the question of humor, which Wallace analyzes in Kafka and which we can notice in the first. Wallace's essay on Kafka, in this sense, will serve as a basis to clarify both, since Wallace points out what seemed relevant to him, namely: Kafka's literal humor. The question of the father, as well as the traumas derived from it, also deserved our attention. Therefore, we aim to bring the authors closer together in order to broaden and clarify both authors and their relations with their own literary work.

KEYwords: David Foster Wallace; Infinite Grace; Franz Kafka.

\footnotetext{
"Doutor em Teoria e História Literária pela Universidade Estadual de Campinas (UNICAMP) e Professor substituto da Universidade Tecnológica Federal do Paraná (UTFPR), Câmpus de Pato Branco. E-mail: diegouab@gmail.com.
} 


\section{ABRINDO O DIÁLOGO}

Herman Broch, em Atualidade de Joyce, ao fazer um balanço da obra joyceana, reconhece o poder simbólico condensador de toda uma época, de toda uma miríade de consciências anônimas que, em conjunto, alimentavam o seu "espírito do tempo":

a grande criação intelectual e artística se torna o portador imediato e concreto de forças em ação na época - claro que com um concreto imediatismo, só próprio ao gênio e que pertence aos seus mais indispensáveis critérios -, elas se torna a criação verdadeiramente nova da época, potencialmente dissolvida nela e na sua ordem, e em tal atualidade, a mais intensiva e imediata possível, a grande obra de arte, a 'obra de arte total'” ('Totalitätskunstwerk') se torna o espelho do Zeitgeist (BROCH, 1992, p. 114-115).

Para Broch, justamente porque se torna uma "obra de arte total", tal criação acaba por superar o seu próprio tempo, já que o preenche e adianta suas próximas linhas de desdobramentos. Com relação ao escritor irlandês, não pairam dúvidas que efetivamente as 18 horas de Bloom e Dedalus ou o circular e lucidamente onírico Finnegans wake dão conta e extrapolam o espírito do tempo das primeiras décadas do século XX.

Lendo Foster Wallace, percebemos que ocorre precisamente o mesmo: nossas paranoias, nossas crises existenciais, nossos vícios, nossas piadas, nossas sacadas, nossas vidas ${ }^{1}$, nossas mortes, tudo parece estar lá ${ }^{2}$. Por isso mesmo, sua obra aponta para algo que ainda não temos, pois está além, como a obra joyceana esteve, da percepção coeva.

Neste artigo, conquanto introdutório e de viés ensaístico, buscaremos analogar comparativamente alguns temas, personagens e atmosferas afins entre Franz Kafka e David Foster Wallace, pois partimos da hipótese que ambos participam de uma proposta estética afim, para a qual literatura e vida compõem um continuum de um mesmo evento ${ }^{3}$. Se era assim (ou não) em um nível pessoal de suas convicções, não convém elucubrar, posto que não nos interessaremos neste sentido biográfico estrito. Contudo, nos interessa o efeito de sentido presente em ambos, a saber: os dois alimentaram, cada um à sua maneira, uma leitura unificadora, totalizante ${ }^{4}$, na qual as agruras do escritor Kaflka são plasmadas em Gregor, por exemplo,

\footnotetext{
${ }^{1}$ Nos delírios (ou não) de Don Gately, o fantasma de Jim Incandenza relata que seu desejo, ao criar filmes de entretenimento, era relatar "a balbúrdia igualitária real dos grupos desfigurantados da vida real, da ágora de verdade do mundo animado" (WALLACE, 2014, p. 854).

${ }^{2}$ Stephen J. Burn, em seu guia do leitor para Infinite jest, coloca o romance na esteira de Ulysses e como caudatário de Pynchon, chamando o romance que ora comentaremos de "encyclopedic project" (BURN, 2003, p. 20).

${ }^{3}$ Mikhail Bakhtin, em trecho famoso de Arte e responsabilidade, conclui dizendo que: "Arte e vida não são a mesma coisa, mas devem tornar-se algo singular em mim, na unidade da minha responsabilidade" (BAKHTIN, 2002, p.XXXIII).

4"Kafka evidentemente não pensa em publicar suas cartas; ao contrário, pensa em destruir tudo o que escreve como se se tratasse de cartas. Se as cartas fazem plenamente parte da obra, é porque constituem uma engrenagem indispensável" (DELEUZE; GUATTARI, 2003, p. 58).
} 
e os personagens suicidas de Wallace tornam o suicídio do autor, para além de um evento biográfico, um evento estético 5 .

Desse modo, a ideia deste trabalho surgiu com a percepção de que algumas questões existenciais, que se desdobram em soluções estéticas, estão presentes em ambos. Evidentemente, Wallace, por vir depois, aproveita-se do legado kafkiano e naturalmente se insere no polo influenciado, embora possamos inverter a noção de causa e efeito historiográficos, ao gosto de um Borges ${ }^{6}$, e encontrar Wallace em Kafka.

Assim, aproximaremos Hal Incandenza e Gregor Samsa a partir da questão da incomunicabilidade, central em ambos. Por outro lado, tendo como base especialmente o ensaio de Wallace a respeito do humor em Kafka, analisaremos passagens do romance Graça infinita à luz do absurdo kafkiano, que se converte eventualmente em graça. Neste périplo,almejamos finalizar com uma percepção melhor de ambos, embora isso signifique termos uma visão mais complexa, densa e trágica do nosso Zeitgeist.

\section{KAFKA E WALLACE: “VOCÊ SÓ PRECISA MUDAR DE DIREÇÃO”}

Segundo Edmund Husserl (Apud KUNDERA, 2009, p. 11), a crise da humanidade europeia se dá quando o "crescimento das ciências impulsionou o homem em direção aos subterrâneos das disciplinas especializadas", gerando, segundo Milan Kundera, o "esquecimento do ser". Husserl e Kundera localizam em Descartes e em Cervantes a criação da modernidade. Ou seja, quando Descartes parte para as coisas extensas (res extensa), quantificáveis, Cervantes, e com ele o gênero romance, passa a ser o meio pelo qual o ser é representado e analisado: os "enigmas do eu" passam a ser a própria matéria do gênero romanesco. Complementa o ensaísta:

O romance não examina a realidade, mas sim a existência. A existência não é o que aconteceu, a existência é o campo das possibilidades humanas, tudo aquilo que o homem pode tornar-se, tudo aquilo de que é capaz. Os romancistas desenham o mapa da existência descobrindo esta ou aquela possibilidade humana (KUNDERA, 2009, p. 46).

Utilizamos a perspectiva de Kundera para embasar nossa concepção de romance, que é um meio estético de delinear aspectos existenciais ora esquecidos pela grande filosofia. Neste sentido, compreendemos que tanto Kafka quanto Wallace enfrentam a condição humana a

\footnotetext{
${ }^{5}$ É digno de nota que o primeiro "texto" de DFW que se espalhou viralmente no Ocidente foi "Isto é água", discurso pronunciado três anos antes de sua morte, no qual a questão do suicídio é mencionada duas vezes abertamente.

${ }^{6}$ Em Kafka y sus precursores, Borges diz: "El hecho es que cada escritor crea a sus precursores. Su labor modifica nuestra concepción del pasado, como há de modificar el futuro" (BORGES, 1980, p. 228).

${ }^{7}$ Referência à Pequena Fábula, de Kafka.
} 
partir de bases estéticas similares em alguns aspectos, os quais serão abordados na sequência deste trabalho.

Adiantando o que veremos em específico, citamos a técnica da inversão, de Kafka, em que um efeito, que trivialmente teria consequências ou reações estrondosas, é posto em suspenso, visto com naturalidade, o que gera o absurdo, aquilo que Günther Anders chamou de "princípio da explosão negativa":

Em Kafka, o inquietante não são os objetos nem as ocorrências como tais, mas o fato de que seus personagens reagem a eles descontraidamente, como se estivessem diante de objetos e acontecimentos normais. Não é a circunstância de Gregor Samsa acordar de manhã transformado em inseto, mas o fato de não ver nada de surpreendente nisso - a trivialidade do grotesco - que torna a leitura tão aterrorizante (ANDERS, 2007, p. 20).

Este recurso, embora não predomine em Wallace, é encontradiço, fato que nos leva a considerá-lo nessa aproximação com o escritor checo. Do mesmo modo, o humor de Kafka (a sua graça, como o chamou Wallace) pode ser frutiferamente associado ao do criador de Infinite jest. Neste sentido, utilizaremos o ensaio de Wallace como referência para compreender melhor o humor kafkiano, ao mesmo tempo em que vislumbramos em Wallace a influência do primeiro.

Adiantamos que esse humor possui sempre algo de absurdo, de "horrível", como outro checo, Milan Kundera, discorre em A arte do romance:

Quando Kafka leu para seus amigos o primeiro capítulo do Processo, todo mundo riu, inclusive o autor [...] o cômico é inseparável da própria essência do kafkiano. Mas é um alivio pobre, para o engenheiro, saber que sua história é cômica. Ele se encontra encerrado na brincadeira de sua própria vida como um peixe num aquário; não acha isto engraçado. Na verdade, uma brincadeira não é engraçada senão para aqueles que estão diante do aquário; o kafkiano, ao contrário, nos leva para dentro, para as entranhas de uma brincadeira, para o horrível do cômico (KUNDERA, 2009, p. 96).

Desse modo, em Wallace, somos levados também para dentro de um aquário ou, inusitadamente, para dentro de um micro-ondas em funcionamento. E aí o riso (irônico ou não) vai perdendo a graça libertadora e ganhando algo de trágico, adensando uma situação humana que, a princípio, parecia somente entreter de modo confortável e previsível.

Neste périplo comparativo, iniciaremos com uma comparação entre dois dos principais personagens dos escritores em análise: Hal Incandenza, de Graça infinita, e Gregor Samsa, de A metamorfose. 


\section{HAL INCANDENZA E GREGOR SAMSA: "EU NÃO SOU O QUE VOCÊS VEEM E OUVEM"}

A título de exemplo, ilustraremos nossa comparação entre personagens olhando para os inícios de A metamorfose e de Graça infinita. Nas duas cenas iniciais, temos os protagonistas sendo vistos e avaliados por outros, os quais nunca conseguem ser apreciados de modo a preservar minimamente suas complexidades interiores; recebem o acabamento(nas palavras de Bakhtin) do outro de modo redutor e despectivo ${ }^{8}$. Embora os sinais externos de ambos encorajem tal atitude diminuidora, somente o leitor das obras é capaz de vislumbrar o interior humano e complexo dos personagens. Somente o livro os redime.

Diametralmente oposto na forma, mas não no conteúdo, o gerente de Gregor, assim como os avaliadores de Hal, direciona suas críticas ao desempenho e afere o valor de cada personagem tendo em vista as possíveis falhas ou embustes: "Nos últimos tempos seu rendimento tem sido muito insatisfatório" (KAFKA, 2011, p. 237). Após tais reprimendas, temos os primeiros reflexos objetivos de como os outros reagem ao ser de Gregor: "Entenderam uma única palavra? - perguntou o gerente aos pais. - Será que ele não nos está fazendo de bobos?” (KAFKA, 2011, p. 239). Vislumbra-se, neste momento, aquilo que ocorrerá progressivamente: uma incomunicabilidade absoluta entre Gregor e os outros.

Na sequência: "Era uma voz de animal - disse o gerente" (KAFKA, 2011, p. 239). Por outro lado, a percepção de Gregor com relação à percepção dos outros também surge, ou seja, a consciência que o outro tem de mim se integra à minha: "Gregor, porém estava muito mais calmo. Certamente não entendiam mais suas palavras", embora para ele elas parecessem claras, mais claras que antes, talvez porque o ouvido havia se acostumado" (KAFKA, 2011, p. 239).

Ao ser visto pelo gerente, este último foge assustado, ao passo que, durante uma página e meia, Gregor discursava, embora ignorado: "Mas o gerente, já às primeiras palavras de Gregor, tinha virado as costas e só lhe dirigia o olhar por cima dos ombros trêmulos, com os lábios revirados" (KAFKA, 2011, p. 243).É bem verdade, a noção de discurso, de linguagem humana, já na primeira das três partes da novela, vai se esvaindo: "na verdade, provavelmente - não tinha sido entendido mais uma vez" (KAFKA, 2011, p. 244).

Desse modo, fica exemplificada a incomunicabilidade que permeia a relação de Gregor com os que o rodeiam (e que se aprofundará até depois de sua morte, quando é removido como um lixo pela empregada).

Já em Graça infinita, percebe-se que o mote fundamental é ouvir e buscar a compreensão do outro, mesmo esbarrando no ceticismo congênito em que estamos: "Mario, eu e você somos

\footnotetext{
${ }^{8} \mathrm{O}$ pai de Jim Incandeza, em relato tocante e existencial, abre-se para o então adolescente filho: "Eu estou com tanto medo de morrer sem jamais ter sido visto de verdade" (WALLACE, 2014, p. 174, grifo do autor).

${ }^{9}$ Evidentemente, neste trecho temos um discurso indireto livre, por meio do qual o narrador de terceira pessoa capta e registra entoações que são próprias a Gregor (técnica esta que se repetirá enquanto o protagonista estiver vivo).
} 
misteriosos um pro outro. A gente está se olhando cada um de um lado de uma diferença intransponível nessa questão. Vamos ficar bem quietinhos e meditar sobre isso" (WALLACE, 2014, p. 45-46), diz Hal àquele que é precisamente o símbolo do esforço máximo para encontrar a alteridade: Mario Incandenza.

A cena inicial de Graça infinita parece ter sido emprestada de Kafka, uma vez que a incomunicabilidade marca o tom da perspectiva de Hal.Além disso, a percepção que os outros têm é sempre incompatível com a autopercepção do protagonista. A narração em primeira pessoa possibilita uma abertura para sua consciência diferente da de Gregor. Contudo, essa abertura acaba sendo solipsista, uma vez que todos os outros, evidentemente, só são outros-para-mim; restando, então, uma narrativa parcial e menos abrangente que a de Kafka.

É sintomático que as primeiras palavras dirigidas a Hal são declarativas de um modo ontológico, nas quais o ser de Hal é imposto desde fora: "Você é Harold Incandenza, dezoito anos [...]" (WALLACE, 2014, p. 8). Daí para frente, as declarações dos membros da reunião vão se acumulando e formando uma imagem disforme e incompatível com o que Hal é (e que o leitor ainda não conhece, como no caso de Gregor). Por outro lado, internamente Hal vai respondendo e antecipando, sempre em silêncio, as percepções da comissão de avaliadores, até que as primeiras palavras que efetivamente são pronunciadas são: "Eu não sou só um brucutu" (WALLACE, 2014, p. 15). A frase, que lembra muito as autoafirmações de um Fabiano, de Vidas secas, reflete, como no caso de Gregor, o incômodo de ter a clara noção de como os outros o veem: "Eu não sou só um carinha que joga tênis. Eu tenho uma história intricada. Experiências e sentimentos. Eu sou complexo" (WALLACE, 2014, p. 16).

Como ocorre no discurso de Gregor diante do Gerente, após uma série de demonstrações de que as desconfianças da comissão eram infundadas ${ }^{10}$, citando Kierkegaard, Camus, Hobbes, Rousseau e outros, a reação deles evidencia que aquilo que chegou somente ao leitor (o qual acompanhou o movimento de consciência) soou de modo monstruoso aos demais: "Santa mãezinha de Deus", "Jesus amado", “O que é que você tem?”, "Chamem alguém!", "Mas, meu Deus do céu, o que são esses...”, um Pró-Reitor grita estrídulo, “... esses barulhos?” (WALLACE, 2014, p. 17). "Mas os barulhos que ele fez." "Indescritíveis." “Como um animal." "Uns sons e barulhos subanimalísticos." "Sem falar nos gestos" (WALLACE, 2014, p. 18). "Nós testemunhamos um negócio só marginalmente mamífero ali dentro, meu amigo.” (WALLACE, 2014, p. 20). Não seria difícil imaginar o Gerente de A metamorfose fazer comentários similares a esses.

Aquele mesmo leitor demorará algumas centenas de páginas para descobrir que aquele comportamento de Hal, somente perceptível pela reação dos demais, está associado

\footnotetext{
${ }^{10}$ Não pairam dúvidas com relação às capacidades intelectuais acima da média de Hal. Acrescente-se às qualidades naturais de um "pródigo lexical", indicando um potencial inato, e à criação em um meio farto em influências intelectuais (neste quesito linguístico, da Mães), o fato que a Academia de Tênis Enfield adere ao sistema escolástico de ensino: Trivium e Quadrivium (cf. WALLACE, 2014, p. 195), reconhecidamente mantenedor da "tradição clássica linha-dura". Outra menção à qualidade e rigidez do ensino clássico baseado nesse modelo medieval se encontra na nota 64 (cf. WALLACE, 2014, p. 1022).
} 
à abstinência de maconha e seus efeitos - ou mais provavelmente pelo uso da DMZ, droga altamente potente apresentada por Pemulis -, já sentidos nos momentos finais do romance. Exclama, então, aquilo que somente os leitores de Kafka e Wallace sabem: "Eu não sou o que vocês veem e ouvem" (WALLACE, 2014, p. 17).

É bem verdade, não partimos de um olhar ingênuo, no qual se creria em um conhecimento pleno e inequívoco do outro, embora também um agnosticismo seja, ao nosso ver, uma postura indevida. Fundamental, neste sentido, é perceber as soluções que cada narrativa oferece para este drama, que é de linguagem e ontológico simultaneamente. Em A metamorfose, diante da postura agnóstica com relação ao ser de Gregor, Kafka dignifica o caixeiro-viajante mantendo-o humano na esfera interior até o último suspiro; por outro lado, a solução $0^{\text {il }}$ familiar foi estabelecer uma cisão entre um Gregor passado e o ser estranho atual, plenamente objetificado, desumanizado: "É preciso que isso vá para fora - exclamou a irmã -, é o único meio, pai. Você simplesmente precisa se livrar do pensamento de que é Gregor. Nossa verdadeira infelicidade é termos acreditado nisso até agora. Mas como é que pode ser Gregor?” (KAFKA, 2011, p. 283).

Por outro lado, em Graça infinita, um dos grandes temas é precisamente ampliar e demonstrar os meios pelos quais o eu de um sujeito se desvela diante de um outro, desde que ambos estejam dispostos a isso. Jim Incandenza, pai de Hal, cria o filmeGraça infinita para tentar dialogar com o próprio filho, missão ridiculamente malfadada no capítulo em que o pai se disfarça de "conversador profissional". Neste sentido, a figura que é a pedra angular de tal solução é Don Gately, que ilustra precisamente a necessidade de sinceridade absoluta no esforço de dizer e de compreender o eu de si e do outro. A frase que dá título a este trabalho: "A verdade liberta, mas só depois de acabar com você" (WALLACE, 2014, p. 400; p. 994) representa Gately, bem como o esforço de Wallace em suas obras por uma dinâmica identidade $\mathrm{x}$ alteridade desprovida de ironia e altamente consciente de suas culpas ${ }^{12}$.

É digno de nota que, durante o ano perdido do romance - e que antecede a cena inicial-, ocorre uma busca ${ }^{13}$ (sobre a qual só temos poucos indícios) no cemitério pela cabeça de Jim Incandenza, e que Hal e Gately, que não se encontram durante todo o livro, a estão desenterrando. Justamente nela (na cabeça) está a cópia máster do Entretenimento ${ }^{14}$. Ou seja, o personagem que representa todo o ímpeto de regeneração e progressão em direção a uma verdade libertadora está com Hal para resgatar o artefato produzido para estabelecer a

\footnotetext{
${ }^{11}$ Recordemos que a "solução final" dos nazistas passava por uma atitude muito semelhante a esta da família de Gregor, a que Hannah Arendt chamou de "homem supérfluo".

${ }^{12}$ Uma alteridade radical como a que propugnava Bakhtin, ao dizer que "Não há álibi para a existência", ou a proposta de um Lévinas, para quem o "rosto do outro" lembra a infinita responsabilidade do eu.

${ }^{13}$ Outra seção seria necessária para comentar o kafkiano destino de Orin, irmão mais velho de Hal, que, na parte final do romance, será sequestrado pelos terroristas cadeirantes e posto em um copo gigantesco, assim como ele fazia com as baratas gigantes do Arizona no início da história(cf. WALLACE, 2014, p. 993).

${ }^{14}$ Era como Jim se referia à produção mais importante: Graça infinita.
} 
comunicação consigo. O problema, que aparentemente já estava em Kafka, é que uma verdade libertadora soa, para nossos céticos ouvidos, pouco crível, fora de moda: "Por que será que a verdade normalmente é não apenas des- mas anti-interessante?” (WALLACE, 2014, p. 368).

Neste sentido, se resguarda um laivo de esperança; mas não qualquer esperança. É adequado recordar o diálogo de Kafka com Max Brod, citado por Walter Benjamin em Franz Kafka - A propósito do décimo aniversário de sua morte: "Existiria então esperanças, fora desse mundo de aparências que conhecemos? Ele [Franz Kafka] riu: há esperança suficiente, esperança infinita - mas não para nós" (BENJAMIN, 1985, p. 142).

\section{O RISO EM KAFKA E WALLACE: “CHEIRINHO DELICIOSO!”}

No intento de ampliar e diversificar nosso périplo comparativo, esta seção do artigo se debruça a respeito do humor de ambos os escritores. Nesse sentido, cumpre dizer que nossa percepção surgiu a partir da leitura do artigo do Wallace a respeito do escritor checo: "Alguns comentários sobre a graça de Kafka dos quais provavelmente não se omitiu o bastante"

De início, Wallace relata sua frustração ao tentar trabalhar com as obras de Kafka, junto aos seus alunos, e tornar visível o peculiar humor kafkiano. O diagnóstico do autor/professor é que cada vez menos o adulto médio norte-americano consegue entender tal humor, o que denota, segundo ele, certa "adolescentização" da cultura média do seu país ${ }^{16}$. O fato de Wallace estar olhando, detectando e salientando tal humor é um indicativo de que, no mínimo, aquilo funcione, que o humor de Kafka possui uma chave em que o riso se abre para questões existenciais mais amplas e, no limite, mais sérias do que o mero e confortável entretenimento. Situações "absurdas, assustadoras e tristes" (WALLACE, 2012, p. 232) são representadas com uma forma tragicômica, em que "boa parte de seu humor é meio carente de sutileza - ou até mesmo antissutil" (WALLACE, 2012, p. 232). Desse modo,como Kundera nos disse acima, estamos "dentro do aquário" e, quando rimos, não é um riso libertador, catártico e confortável: "a comédia em Kafka também é sempre tragédia, e essa tragédia também é sempre uma imensa e reverente alegria" (WALLACE, 2012, p. 233).

Mas qual é essa forma, qual é o método para atingir tal efeito? Wallace aponta com simplicidade, que é característica dos grandes achados críticos, sua tese: "Meu argumento é que a graça de Kafka depende de uma espécie de literalização radical de verdades que tendemos a tratar como metafóricas" (WALLACE, 2012, p. 233). Desse modo, o dispositivo que provoca o riso está na superfície e não em algum trocadilho ou sacadas acompanhadas de piscadelas ao leitor arguto.

\footnotetext{
${ }^{15}$ Coligido no Ficando longe do fato de já estar meio que longe de tudo (2012).

${ }^{16} \mathrm{Um}$ dos narradores mais sofisticados e ponderados do romance, analisando o caso de Hal, chama a este fenômeno de "puberdade espiritual" (WALLACE, 2014, p. 710).
} 
Exemplos desta "literalização radical" podem ser encontrados no próprio Wallace. Iniciamos mencionando Lyle, o guru-fitness, que é apresentado nos seguintes termos:

Esse guru vive do suor dos outros. Literalmente. Dos fluidos, sais e ácidos graxos. Ele é como um louco de estimação [...] Você faz tipo umas séries de supinos, umas séries de supinos, umas flexões de perna, uns abdominais inclinados, retos, fica bem laqueadinho de suor; aí, se você deixar ele te lamber os braços e a testa, ele te transmite alguma pepita da sabedoria de um guru-fitness (WALLACE, 2014, p. 133).

Neste trecho, gostaríamos somente de evidenciar que o elemento de riso que há na personagem deriva da literalização da expressão "viver do suor dos outros". De tão inusitada, esta construção prontamente é tomada de modo metafórico, o que torna cômica e, para dizer pouco, insólito; conquanto não haja nada de trágico.

Na mesma linha de Lyle, as irmãs gêmeas Vaught assim são apresentadas:

as infames gêmeas Vaught da ATE, Caryn O’ e Diva Dee Vaught, dezessete anos, dupla feminina número um do ranking júnior da ONAN, invictas há três anos, um duo invencível, com um entendimento sobrenatural em quadra, movendo-se sempre como Uma-Só, jogando não só como se compartilhassem, mas de fato porque compartilham um mesmo cérebro, ou ao menos os lobos psicomotores de um mesmo cérebro, as gêmeas siamesas, unidas pelas têmporas esquerda e direita, proibidas de jogar simples pelos regs. da ONAN, as impressionantes e aterradoras Vaught, obstinadas filhas de executivos de executivos de fábricas de pneus lá de Akron, usando suas quatro pernas para cobrir áreas espantosamente amplas da quadra em que joga/jogam (WALLACE, 2014, p. 225).

Novamente, o riso surge justamente da inversão do nível metafórico (inferido naturalmente pelo leitor) em direção ao nível literal, em que toda a descrição, feita de modo objetivo, gera um humor que prenuncia o desconforto kafkiano, encontrado definitivamente nos dois exemplos que veremos agora.

Outro episódio que ilustra a literalização do humor - agora com um desdobramento trágico -é este em que a morte de uma mulher é descrita de modo literal e, por isso mesmo, com a graça típica de Kafka, segundo o apontamento do próprio Wallace:

A portadora do Coração Artificial Externo Jarvik IX de quarenta e seis anos estava ativamente olhando vitrines na elegante Harvard Square de Cambridge, Massaschusetts, quando um trombadinha travestido, um viciado em drogas com uma ficha criminal conhecidíssima dos administradores da coisa pública [...] brutalmente arrancou da desatenta 
mão da mulher a bolsa que lhe sustinha a vida. A ativa e alerta mulher perseguiu 'a' trombadinha enquanto pôde, lamuriosamente gritando aos passantes as palavras 'Segurem aquela mulher! Ela roubou meu coração!' na elegante calçada repleta de gente fazendo compras, aparentemente gritando repetidamente: 'Ela roubou meu coração, segurem aquela mulher!'. Em resposta a suas lamúrias, tragicamente, os equivocados passantes e populares meramente sacudiam a cabeça olhando de um para o outro [...] (WALLACE, 2014, p. 148).

Trata-se de uma notícia de jornal, daí o estilo da narração com um tom sensacionalista. Novamente, o riso eclode precisamente da expressão que está denotando com perfeição o ocorrido. Contudo, a metáfora está tão incrustada aos signos linguísticos em questão que o presumível contexto, envolvendo um relacionamento amoroso não correspondido ou acabado, irrompe nos transeuntes. Todos riem do lado de fora do aquário; a mulher, desgraçada, dentro do aquário, agoniza: "Acontece toda hora”, diz uma dupla de policiais.

Nesse elenco do riso, não poderíamos deixar de comentar o verdadeiro artífice desta graça corrosiva e trágica: Jim Incandenza. O filme Graça infinita é o próprio símbolo deste riso trágico, o sorriso extasiado nos lábios daqueles que, como o adido médico do Oriente Próximo desfrutam do “o prazer feliz da pessoa sozinha, não?”, pergunta Hal aos colegas de Enfield.

Em um diálogo fundamental para se conhecer tanto Hal quanto Orin, ambos, por telefone, como que cumprem o luto paterno, detalhando o evento fatídico, testemunhado primariamente por Hal. Importante apontar que esse diálogo desdobra as várias seções psiquiátricas pelas quais passou o jovem tenista, resultando em uma verdadeira (?) catarse:

Quando eu tinha acabado de entrar e ainda estava no hall tentando tirar o sapato sem largar a sacola de roupa suja no carpete branco e pulando num pé só, e ninguém podia esperar que eu tivesse alguma ideia do que tinha acontecido. Eu disse que ninguém consegue escolher ou ter controle das primeiras ideias e reações inconscientes quando entra numa casa. Eu disse que não era minha culpa que a minha primeira ideia inconsciente acabou sendo... 'Jesus amado, garoto, fala' 'Que alguma coisa ali estava com um cheirinho delicioso!', eu gritei (WALLACE, 2014, p. 264).

Este diálogo, permeado de unhas sendo cortadas e milagrosamente sendo acertadas no lixo, ilustra toda a potência do humor wallaciano/kafkiano: o suicídio paterno, que, apresentado a partir de uma sincera e literal descrição, provoca riso. Note-se que a confissão de Hal é libertadora, pois ao tergiversar o jovem dá indicativos de recalque, de luto mal resolvido e sensação de culpa mediante o prazer olfativo associado aos miolos paternos. Seguramente, um humor peculiar e invulgar; por essa razão: "Não admira que eles sejam incapazes de compreender a verdadeira piada fundamental em Kafka: a de que o esforço terrível de estabelecer um self 
humano resulta num self cuja humanidade é indissociável desse esforço terrível" (WALLACE, 2012, p. 235).

Neste sentido, cabe acrescentar que é um humor libertador desde um nível muito mais profundo e, abre aspas, "real", uma vez que, inclusive no caso de Hal, abre para uma percepção genuína de si e da realidade concreta. Neste sentido, Wallace aponta em Kafka que seu humor "nada tem de neurótico, mas é antineurótico, heroicamente sadio - é, finalmente, um humor religioso" (WALLACE, 2012, p. 234). Um humor que religa, que restabelece, ao invés de criar camadas irônicas ou risinhos de canto, que afastam e diminuem nosso contato com o outro, com o mundo e, ipso facto, com nosso próprio eu. Definitivamente, a "espirituosidade de Kafka [é] inacessível a jovens que nossa cultura treinou para ver piadas como entretenimento e entretenimento como conforto" (WALLACE, 2012, p. 234).

\section{RESSONÂNCIAS PATERNAS: "SE ELE NOS ENTENDESSE"17}

É possível resumir em linhas muitíssimo gerais o enredo de Graça infinita à influência do pai sobre os filhos: "Perhaps more importantly, though, as Infinite jest is a novel that explores the different ways 'fathers impact sons"' (BURN, 2003, p. 42). É bem verdade, como a menção a Hamlet indicada no título do romance faz notar, trata-se da relação dos pais entre si e na relação com os filhos ${ }^{18}$.

Um episódio kafkiano ilustra a relação entre Sipróprio ${ }^{19}$ e seu pai: no inverno de 1963, o pai promove um conserto da sua cama, que enigmaticamente está rangendo e emitindo sons, segundo ele, de roedores, motivo pelo qual o colchão do casal é arrastado, até que então a secreta sujeira de pó aparece. Uma indireta e nada sutil sequência de reclamações direcionadas à mãe de Jim começa a surgir a todo momento em que as grossas camadas de pó são descobertas: "Jesus, está até cheirando [...] Essa merda está até cheirando" [...] "No mandato de que presidente fizeram uma faxina geral neste quarto, eu me vejo aqui inclinado a pensar em voz alta" (WALLACE, 2014, p. 510). Jim, auxiliando o pai, é sempre interrompido ou rudemente ordenado a apanhar algo. Até que:

Bem nessa hora, eu me lembro, houve um som violento e a minha área da estrutura saltou de repente quando o mal-estar de meu pai o fez desmaiar, e ele perdeu o equilíbrio, caiu para a frente, ficou em decúbito ventral e desmaiado sobre seu lado da estrutura da cama, que enquanto eu me afastava da estrutura e me punha de joelhos vi que estava ou quebrada ou bem torta. Meu pai tinha caído de cara na mistura do

\footnotetext{
${ }^{17}$ Frase que o pai de Gregor Samsa repete duas vezes na parte final da novela.

${ }^{18}$ Diz o pai de Jim a ele: "Jim, eu estou te dizendo que você não consegue imaginar a minha ausência" (WALLACE, 2014, p. 174).

19 “A gente chama ele de Sipróprio. Tipo aspas 'o homem em si próprio”' (WALLACE, 2014, p. 34).
} 
pó espesso do retângulo com o material que havia regurgitado de seu estômago desarranjado. A poeira que seu desmoronamento levantou era muito grossa, e à medida que a nova poeira subia e se espalhava ela atenuava a luz da suíte máster [...] A peruca profissional de meu pai tinha se deslocado e estava com o escalpo virado para cima na mistura de pó e material estomacal. O material estomacal me parecia consistir basicamente de sangue gástrico até eu me lembrar do suco de tomate que meu pai tinha bebido. Ele estava caído de cara, com a bunda para cima, sobre a lateral da estrutura da cama, que seu peso tinha partido em duas. Entendi que havia sido essa causa do som violento e súbito (WALLACE, 2014, p. 512).

A reação esperada seria o socorro imediato, dada a grotesca e tensa situação. Contudo, “o espantoso, em Kafka, é que o espantoso não espanta ninguém” (ANDERS, 2007, p. 20); nesse caso, o espantoso, em Wallace, não espanta nem filho nem mãe. "Licença”, pede Jim ao passar pisando pelo meio das pernas do pai; "obrigada”, responde a mãe agradecendo a ajuda do filho "enquanto transcorria um longo período de um silêncio tão completo" (WALLACE, 2014, p. 513). Encerrar-se a seção e o estado do pai não retorna à narrativa, confirmando a observação de Carlisle: "Wallace concludes a narrative sequence in 'chaotic stasis' or at a moment of maximum tension" (CARLISLE, 2007, p. 20).

No entanto, nos interessa o que derivou da problemática relação Jim-Hal enquanto efeito em e por Hal, como resume Carlisle: "Parent-child relationships are significant in Infinite jest as they are Hamlet. Hal's father had trouble communicating with Hal's grandfather and believes he must resort to a disguise to communicate with Hal. Hal's father is obsessed with the idea that Hal is silent' (CARLISLE, 2007, p. 21).

Temos contato com essa obsessão paterna, especialmente no espectral “diálogo" entre o fantasma de Jim e o combalido Don Gately:

O menino, que fazia tudo bem e com uma graça descorcunda e natural que o próprio espectro nunca tivera, e que o espectro queria tão terrivelmente ver, ouvir e fazer com que ele (filho) soubesse que era visto e ouvido, o filho tinha se tornado um menino cada vez mais oculto mais para o fim da vida do espectro [...] Horror nenhum na terra ou em outro lugar se compara a ver o teu próprio rebento abrir a boa e nada sair (WALLACE, 2014, p. 856).

Em função deste horror, em grande medida uma projeção de suas (de Jim) neuroses e frustrações, o pai explora na arte um modo de realizar um projeto suficientemente complexo e atraente para que o filho saia deste suposto mutismo. Nesta mitologia familiar ${ }^{20}$, em que

\footnotetext{
${ }^{20} \mathrm{Em}$ trabalho futuro, pretendemos desenvolver as analogias mitológicas presentes em Graça infinita. Stephen J. Burn explora introdutoriamente a relação Don Gately - Hércules, mas não avança nas relações de Gately com outros persona-
} 
pais vão castrando filhos ${ }^{21}$, Jim é o fantasma redivivo, como no caso da peça de Shakespeare, que revela seu intento com clareza:

O espectro corre os dedos por sua longa mandíbula e diz que passou todos os últimos noventa dias sóbrios da sua vida animada trabalhando incansavelmente para tentar conceber um instrumento via o qual ele e o filho tácito pudessem simplesmente conversar. Inventar algo que o menino talentoso não conseguisse simplesmente dominar e passar adiante, rumo a um novo platô. Algo que o menino amasse tanto que pudesse induzi-lo a abrir a boca e sair nem que fosse só para pedir mais. Os jogos não tinham dado certo, profissionais não tinham dado certo, a imitação de profissionais não tinha dado certo. Sua última saída: entretenimento. Fazer alguma coisa divertida pra cacete, que reverteria a inércia da queda de uma jovem alma rumo ao útero do solipsismo, da anedonia, da morte em vida. Um brinquedo magicamente divertido pra sacudir na frente dos olhos do bebê ainda vivo naquele menino, pra deixar os olhos dele brilhando e aquela boca sem dentes inconscientemente aberta, para rir. Para deixá-lo 'fora de si', como eles dizem. O útero podia ser usado dos dois jeitos. Uma forma de dizer EU SINTO TANTO, TANTO e ser ouvido. O sonho de toda uma vida. Os acadêmicos, as Fundações e os disseminadores nunca viram que o desejo mais sério dele era: entreter (WALLACE, 2014, p. 857).

Como Odisseu deseja ver Telêmaco amadurecendo ${ }^{22}$, Abraão anela um substituto para Isaac, Leopold Bloom vislumbra uma superação para seu filho espiritual: Stephen Dedalus, e um largo etc. As comparações seriam inúmeras, mas a solução para este drama milenar, aqui em Wallace, é peculiar: oferecer um artifício que possa entreter de modo potencialmente irresistível, que acaba se tornando uma arma letal, como Marathe vaticina: "Um EUA que morreria - e deixaria seus filhos morrerem, cada um - pelo suposto perfeito Entretenimento, por esse filme" (WALLACE, 2014, p. 328).

Por outro lado, Hal, de fato, encena um progressivo emudecimento, simbolizado pela reclusão no subsolo da Academia para usar maconha e, posteriormente, pelos efeitos da abstinência dela, que desencadearam a incomunicabilidade descrita na cena inicial do romance, no Ano Feliz. Outros personagens, ainda no Ano da Fralda Geriátrica Depend, percebem a mudança em Hal, em especial o seu irmão, Mario.

Para ampliarmos a discussão em torno de Hal e Jim, vejamos o caso do protagonista de A metamorfose, segundo Deleuze e Guattari:

gens ou mesmo as analogias possíveis de outros mitos dentro da trama de Wallace.

${ }^{21}$ As primeiras palavras do pai de Jim a ele são: “Jim não assim Jim” (WALLACE, 2014, p. 162).

${ }^{22}$ Realizando sua Telemaquia, ou seja, para dizer como Werner Jaeger, em Paideia, cumprindo sua "aristeia”, a saber: encontrando sua areté. 
Gregor se torna barata, não apenas para fugir de seu pai, mas antes para encontrar uma saída onde seu pai não a soube encontrar, para fugir do gerente, do comércio e dos burocratas, para atingir essa região onde a voz apenas murmura - 'Você o ouviu falar? Era uma voz de animal, declarou o gerente' (DELEUZE; GUATTARI, 2003, p. 34).

Os críticos entendem que a metamorfose é uma espécie de "linha de fuga" de Gregor, a única possibilidade de fugir às injunções que o coisificam. De certo modo, a linha de fuga de Hal acaba sendo aquilo que, mutatis mutandis, o faz escapar daquilo que sempre esperaram que fosse: gênio e atleta prodígio. Ao ser flagrado como um animal, já no capítulo de abertura do romance, Hal se encontra protegido, como Gregor estará, em uma carcaça (aquilo que o outro contempla) avessa ao que se espera dele. Embora ambos tenham que se sujeitar aos outros neste estado animalizado, a liberdade interna acaba sendo mantida, como os leitores (e somente eles) percebemos.

Páginas e mais páginas foram escritas, descrevendo e analisando a relação pai-filho em Kafka. Interessa-nos somente analogar ao caso Wallace, para daí sairmos com mais luzes compreensivas de ambos. A respeito deste tópico, dizem Deleuze e Guattari: "A questão do pai não se trata de saber como tornar-se livre em relação a ele (questão edipiana), mas como é que se encontra um caminho onde ele não encontrou nenhum" (DELEUZE; GUATTARI, 2003, p. 29).

Desse modo, embora haja saída para os personagens de Kafka e Wallace, ela nunca é simples e, muito menos, eufórica. Se a esperança não é para nós, como Kafka disse, ela só poderá ser para outros mediante um enfrentamento sincero, verdadeiro e idealista - tudo isso sem aspas e sem itálico.

\section{CONSIDERAÇÕES FINAIS: "PEÇO DESCULPAS A TODOS"}

As últimas palavras do Artista da fome, de Kafka, são "Peço desculpas a todos" (KAFKA, 2011, p. 57). Pedir desculpas é assumir a culpa, no sentido mais profundo do termo, como os membros da Casa Ennet aconselham.

Neste ensaio, buscamos relacionar dois mundos separados contextualmente, mas próximos humanamente. Kafka e Wallace parecem dialogar tópicos fundamentais, tais como a condição humana e sua culpa inerente, a relação paterna conflituosa, o tipo de humor representado e um enfrentamento verdadeiro e drástico, na literatura, de questões humanas fundamentais. Como Wallace aponta em Dostoiévski, no ensaio/resenha já citado aqui, vemos uma postura corajosa:

Para mim, o mais surpreendente e inspirador de Dostoiévski não é só que ele foi um gênio, mas que também foi valente. Nunca deixou de se preocupar com sua reputação literária, mas tampouco deixou de 
promulgar coisas que não estavam na moda e nas que ele acreditava. E não o fez deixando à margem (o que agora se diria 'transcendendo' ou 'subvertendo') as circunstâncias culturais hostis nas quais estava escrevendo, mas afrontando-as e lutando com elas, de forma específica e chamando-as por seu nome (WALLACE, 2008, p. 335).

Fundamental perceber que aquilo que buscamos relacionar e elucidar em Wallace e Kafka, especialmente na seção final do artigo, é apontado, não só como diferencial, mas como um modelo que, se adequado às circunstâncias hostis de seu tempo, resulta no tipo ideal de literatura a ser feita. Como fica evidente na citação final:

Tendo em vista este fato (e é um fato), quem é o culpado pela falta de seriedade de nossa narrativa séria? A cultura, as risadas? Mas não ririam (não poderiam) se uma obra de ficção moralmente apaixonada e apaixonadamente moral fosse também uma narração engenhosa e radiantemente humana. Mas como conseguir isso? Como pode um escritor de hoje em dia, até um escritor com talento de hoje em dia, tomar coragem para sequer tentá-lo? Não existem fórmulas nem garantias. Mas, sim, existem modelos. Os livros de Frank fazem com que um deles seja concreto e esteja vivo e resulte terrivelmente instrutivo (WALLACE, 2008, p. 337).

Esperamos ter demonstrado que as instruções de Kafka e Dostoiévski foram aderidas por Wallace, já que há ressonâncias de sobra entre as vozes elencadas. Esperamos, também, que esta obra de arte total para o nosso tempo ("Totalitätskunstwerk"), que é a de Wallace, também nos seja instrutiva quanto ao seu conteúdo, não moral, mas humano, demasiado humano.

\section{REFERÊNCIAS}

ANDERS, G. Kaflka pró e contra: os autos do processo. Tradução: Modesto Carone. São Paulo: CosacNaify, 2007.

BAKHTIN, M. Arte e responsabilidade. In: Estética da criação verbal. Tradução: Paulo Bezerra. São Paulo: Martins Fontes, 2002.

BENJAMIN, W. Franz Kafka - A propósito do décimo aniversário de sua morte. In: BENJAMIN, W.Magia e técnica, arte e política. São Paulo: Brasiliense, 1985. p. 141-142.

BORGES, J. L.Kafka y sus precursores. In: Prosa completa. v. 2. Barcelona: Bruguera, 1980.

BROCH, H. Atualidade de Joyce. In: NESTROVSKI, A. (Org.). Riverrun: ensaios sobre James Joyce.Tradução: Jorge Wanderley; Lya Luft; Marco Lucchesiet al. Rio de Janeiro: Imago Ed., 1992. 
BURN, S.J. David Foster Wallace's Infinite jest: a reader's guide. Nova York/Londres: Continuum, 2003.

CARLISLE, G. Elegant complexity: a study of David Foster Wallace's Infinite jest. Los Angeles: Sideshow Media Group, 2007.

DELEUZE, G.; GUATTARI, F. Kafka: para uma literatura menor. Tradução: Rafael Godino. Lisboa: Assírio \& Alvim, 2003.

GALINDO, C. Um tipo americano de tristeza: o próximo romance de David Foster Wallace e os próximos romances americanos. Outra travessia, n. 7, p. 125-138, out. 2009. Disponível em: https://periodicos.ufsc.br/index.php/Outra/article/view/11984. Acesso em: 20 jun. 2020.

KAFKA, F. A metamorfose. In: Essencial Franz Kaflka. Tradução: Modesto Carone. São Paulo: Penguin Companhia das Letras, 2011.

KUNDERA, M. A arte do romance. Tradução: Teresa Bulhões Carvalho da Fonseca. São Paulo: Companhia das Letras, 2009.

WALLACE, D. F. Ficando longe do fato de já estar meio que longe de tudo. Tradução: Daniel Galera; Daniel Pellizzari. Seleção e prefácio de Daniel Galera. São Paulo: Companhia das Letras, 2012.

WALLACE, D. F. Graça infinita. Tradução: Caetano W. Galindo. São Paulo: Companhia das Letras, 2014.

WALLACE, D. F. Hablemos de langostas. Tradução: Javier Calvo. Buenos Aires: DeBolsillo, 2008.

Recebido para publicação em: 14 jul. 2020.

Aceito para publicação em: 8 abr. 2021. 